\title{
Failure Envelopes of Composite Bucket Foundation for Offshore Wind Turbines under Combined Loading with considering Different Scour Depths
}

\author{
Yuanxu Jing, ${ }^{1}$ Yuan Wang, ${ }^{1}$ Jingqi Huang $\mathbb{D}^{1},{ }^{1}$ Wei Wang, ${ }^{1}$ and Lunbo Luo ${ }^{2}$ \\ ${ }^{1}$ School of Civil and Resource Engineering, University of Science and Technology Beijing, Beijing 100083, China \\ ${ }^{2}$ Institute of Science and Technology, China Three Gorgers Corporation, Beijing 100038, China \\ Correspondence should be addressed to Jingqi Huang; huangjingqi11@163.com
}

Received 15 June 2021; Accepted 29 July 2021; Published 13 August 2021

Academic Editor: Piguang Wang

Copyright (c) 2021 Yuanxu Jing et al. This is an open access article distributed under the Creative Commons Attribution License, which permits unrestricted use, distribution, and reproduction in any medium, provided the original work is properly cited.

\begin{abstract}
The composite bucket foundation of offshore wind turbines is subjected to a variety of loads in the marine environment, such as horizontal load $H$, vertical load $V$, bending moment $M$, and torque $T$. In addition, due to the characteristics of its connection section, the water flow around the foundation will produce scour pits of various degrees, reducing the depth of the bucket foundation, which has a nonnegligible impact on the overall stability of the bucket foundation. In this paper, the failure envelope characteristics of different combinations of loads on bucket foundations, including $V-H-T, V-M-T$, conventional $V-H-M$, and noncoplanar $V-H-M$, are numerically investigated with considering different scour depths. The numerical results indicate that the $V-H-T, V-M-T$, conventional $V-H-M$, and noncongruent $V-H-M$ failure envelopes gradually shrink inwards with increasing scour depth, and the stability of the composite bucket foundation decreases; the conventional $V-H-M$ failure envelope shows an asymmetry of convexity to the right, and the noncongruent $V-H-M$ failure envelope shows an asymmetry of outward convexity to the left and right. The corresponding mathematical expressions for the failure envelope are obtained through the normalized fitting process, which can be used to evaluate the stability of the bucket foundation based on the relative relationship between the failure envelope and the actual load conditions, which can provide practical guidance for engineering design.
\end{abstract}

\section{Introduction}

As a clean and renewable energy source, offshore wind power is rapidly developing due to its advantages of less turbulence, not occupying arable land, and less impact on the environment $[1,2]$. As a new kind of foundation of offshore wind power, composite bucket foundations have the advantages of convenient transportation, low installation cost, and cyclic utilization, which have great promise future in the offshore wind turbine industry [3-7]. In the actual marine environment, the composite bucket foundation is subjected to a complex load situation, not only by the longterm self-weight load $V$ of the wind turbine superstructure but also by the horizontal load $H$, the moment load $M$, and the torque load $T$ transmitted by the wind turbine blade structure [8-10]. Therefore, the bearing capability of the composite bucket foundation is an important problem in offshore wind power engineering.

In the last decades, lots of research studies have been conducted to study the bearing capability of the composite bucket foundation by many scholars. Liu et al. [11] systematically investigated the effects of the dimensional parameter on the resistance of the composite bucket foundation under moment loads, as well as the failure mechanism of the composite bucket foundation and the locations of the foundation rotation points. Liu et al. [12] investigated the ultimate bearing capacity of the composite bucket foundation under vertical loading with the aid of the model test and classical plasticity theory. Liu et al. [13] studied the horizontal bearing capacity characteristics of the composite bucket foundation in silty clay soil through a large size model test. The distribution law of earth pressure, the 
mechanism of displacement variation, and the ultimate bearing capacity of composite bucket foundations under horizontal loading were also investigated. Jia et al. [14] studied the ultimate bearing capacity of the composite bucket foundation under horizontal loading by field test. The variation law of soil pressure and the rotation center of the bucket was obtained. The above studies are mainly focused on the bearing capability of the composite bucket foundation under a single load, such as vertical load, moment load, and horizontal load. Ding et al. [15] determined the horizontal ultimate bearing capacity of the composite bucket foundation by field tests. In addition, the failure envelope properties of the $H-M$ combined load were investigated by numerical simulation. With the aid of finite element modeling, Liu et al. [5] investigated the buckling failure models of the composite bucket foundation under vertical loads and modified the theoretical formulation. Moreover, the $H-M$ failure envelope and the three-dimensional $V-H-M$ failure envelope properties were also discussed. Ding et al. [16] studied the combined loading characteristics of the composite bucket foundation in sandy soil and found that appropriate vertical loading can significantly increase the horizontal and moment ultimate bearing capacity of the foundation. Considering the cycle characteristics of ocean loadings, Wang et al. [17] investigated the failure characteristics of the composite bucket foundation under constant and variable amplitude cyclic loadings by model tests and given the stiffness and damping change laws of the foundation. The above studies have primarily focused on the effect of load types on the bearing capability of the composite bucket foundation, without considering the defects of the foundation soil.

The composite bucket foundation is generally wide and shallow. The water flowing around the foundation tends to produce a scouring vortex, which will take away the soil around the foundation and form different degrees of the horseshoe-shaped scouring pit. The scouring pits can significantly reduce the burial depth of the foundation and consequently affect the bearing capacity and stability of the foundation $[9,18]$. Yu et al. [18] investigated the scour characteristics of unidirectional flow action on composite bucket foundations by a series of scale model tests. With experimental tests, Chen et al. [19] investigated the effect of scouring on the stability of the bucket foundation subjected to cyclic wave loading and found that the stability of the foundations gradually decreased as the depth of scouring increased. Zhao et al. [9] studied the load-bearing characteristics of the composite bucket foundation under different scour depths and scour ranges through the finite element method. Lu et al. [20] numerically analyzed the variation in the vertical ultimate bearing capacity and the foundation failure mechanisms of the bucket foundation in silty clay soil under unilateral scour conditions. Zhang et al. [21] investigated the bearing capacity characteristics of the bucket foundation in sandy soil foundations under wave loading and scouring through model tests and finite element analysis. Although some studies have been carried out to investigate the effect of scouring on the bearing capacity of the bucket foundation, these studies are limited to the impact of scour depth or scour extent on the unidirectional bearing capacity. Offshore wind engineering structures suffer a variety of loads throughout their service. However, few scholars have investigated the effect of scouring on the bearing capacity of the composite bucket foundation under complex loads.

In this study, the effect of scour depth on the bearing capacity of the composite bucket foundation supporting offshore wind turbines is numerically investigated, which are subjected to different load combinations. A finite element model was established first, and the finite element model was verified by comparison with model tests. Then, the characteristics of the failure envelope of the composite bucket foundations are analyzed, considering different scour depths and loading conditions, such as $V-H-T, V-M-T$, conventional coplanar $V-H-M$, and noncongruent $V-H-M$ combined loadings. Finally, concluding remarks are offered.

\section{Finite Element Model and Numerical Methods}

2.1. Model Geometry and Mesh. Composite bucket foundations are widely used in foundations with shallow embedment depths. Compared to deep foundations, the reduction in burial depth caused by scouring is more detrimental to composite bucket foundations. In this paper, the scouring pit of a composite bucket foundation was simplified. A schematic diagram of the scouring structure is shown in Figure 1.

The composite bucket foundation contains three parts: the upper concrete transition section, the central beam slab structure, and the lower circular steel bucket structure with splitter slabs, as shown in Figure 2. Similar to a honeycomb structure, the lower circular steel bucket structure always has seven rooms, with a regular hexagon in the middle [22]. The study in this paper focuses on the load-bearing characteristics of the lower circular steel bucket. Therefore, only the circular steel bucket was modeled, considering that the structure in direct contact with the soil is a lower circular steel bucket, and the load is an equivalent concentrated load on the top of the bucket $[2,9]$.

Figure 3 shows the finite element model of the composite bucket foundation located in homogeneous marine soil. The bucket foundation is steel construction with a diameter of $30 \mathrm{~m}$ and a height of $12 \mathrm{~m}$, respectively. To effectively avoid the boundary effect generated by the truncated boundary of the soil ground, the ground part is built with a very large cylindrical shape. The diameter and height of the ground part are $150 \mathrm{~m}$ and $60 \mathrm{~m}$, respectively, which are five times larger than the corresponding sizes of the foundation. The bottom and lateral boundaries of the soil domain are fixed in the normal direction.

Following other studies [5, 8, 22], an ideal elastic model is used for simulating the circular steel bucket with Young's modulus $E$ of $210 \mathrm{GPa}$, Poisson's ratio $v$ of 0.3 , and a density of $7850 \mathrm{~kg} / \mathrm{m}^{3}$. Most of the Chinese coast is silty sand according to the relevant studies that have been conducted, and an elastic-perfectly plastic Mohr-Coulomb model is adopted to simulate the soil $[9,15]$, with Young's modulus $E$ 


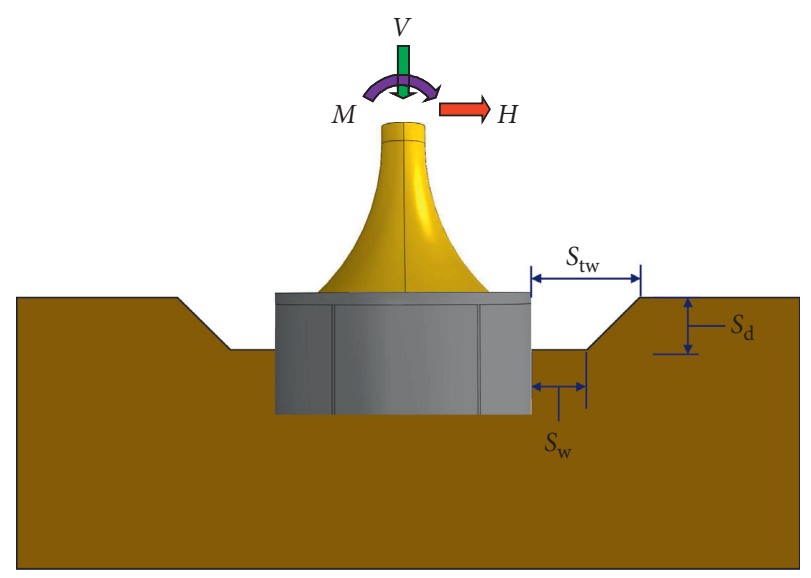

Figure 1: Structure diagram of the composite bucket foundation.

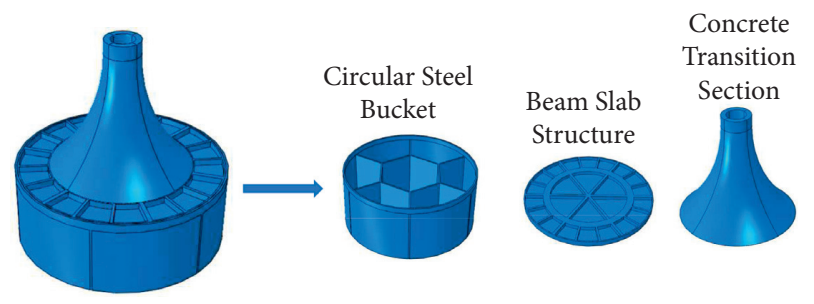

FIgUre 2: Composite bucket foundation.

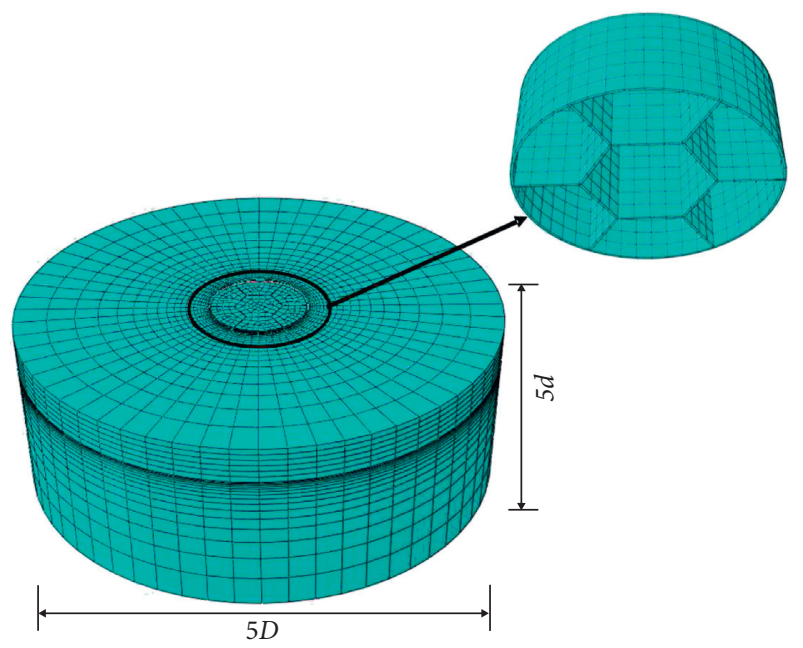

FIgURE 3: Finite element.

of $18.44 \mathrm{MPa}$, Poisson's ratio $v$ of 0.35 , cohesion $c$ of $3.84 \mathrm{kPa}$, and an internal friction angle $\varphi$ of $7.14^{\circ}$. Frictional contact is used between the composite bucket foundation and the soil, which allows the interface to detach, with an interface friction coefficient of 0.35 [9]. Both the bucket foundation and the soil ground are discretized by the hexahedral eight-node (C3D8R) element. By model tests, Yu et al. [18] investigated the maximum scour depth of $3.5 \mathrm{~m}$ for a composite bucket foundation under the scouring action of unidirectional flow. Therefore, the scour pit range $S_{w}$ $\left(S_{\mathrm{tw}}=S_{w}\right)$ is taken as $0.16 \mathrm{D}$ in this paper, and the scour depth $S_{\mathrm{d}}$ is taken as $d / 12, d / 6$, and $d / 4$, respectively.
2.2. Loading Method and Cases. The loading methods of displacement-controlled swipe tests and fixed displacement ratio probe tests are commonly used for establishing the failure envelope of combined loading.

The displacement-controlled swipe test was first proposed in [23] and consists of two main steps, as illustrated in Figure 4, which have been widely employed to numerically investigate the bearing capability of the foundation [24-26]. First, a given displacement $u_{i}$ is applied to the foundation along a certain direction starting from zero until the ultimate bearing capacity is reached. Subsequently, the displacement $u_{j}$ is loaded in another different direction until it corresponds to the ultimate load capacity while remaining constant in the first step of loading. Loading paths developed at this time can be used as the failure envelope of the bucket foundation, as shown in Figure 5. This method is generally applied to the $V-T, V-M$, and $V-H$ failure envelopes.

A fixed displacement ratio probe test is applied to displacements along with the two different directions, during which the proportion of displacement remains constant. A loading path can be obtained under these loading conditions. Based on the characteristic that the loading path will converge to the failure envelope, a limited point on the failure envelope can be determined. By varying the displacement proportion, the ultimate bearing capacity is obtained for different displacement proportions [8, 27, 28]. In this study, to determine the failure envelope, a certain vertical load $V$ is applied first and then different proportions of the displacement loads $u / \vartheta$ are carried out.

Considering the composite bucket foundation service in combined loading situations where multiple loads such as horizontal load $H$, vertical load $V$, bending moment $M$, and torque $T$ act together, a certain loading method and sequence are needed to obtain an authentic and accurate ultimate bearing capacity. Therefore, this paper adopts the suggestions of [29] for a combined planar $V-H-M$ loading sign specification, as shown in Figure 6.

2.3. Model Validation. To verify the validity of the finite element model, the load-displacement curve of the composite bucket foundation under horizontal load is simulated. The parameters of the FEM keep step with those of the experimental test conducted by [15], including the composite bucket dimensions, soil parameters, and loading methods. Figure 7 offers the load-displacement curve of the bucket foundation under horizontal load by the numerical results and the experimental results. Compared with the previous experimental results, the calculation results of the finite element model have good agreement with the previous experimental results, which indicates that the adopted finite element model is reliable.

\section{Numerical Results}

3.1. Unidirectional Ultimate Bearing Capacity of Composite Bucket Foundations under Different Vertical Loads. The ultimate bearing capacity of a composite bucket foundation loaded in one direction with a displacement-controlled 


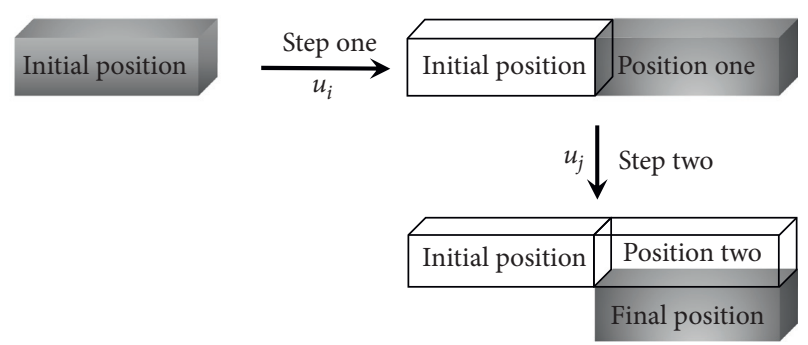

Figure 4: Diagram of the displacement-controlled swipe test.

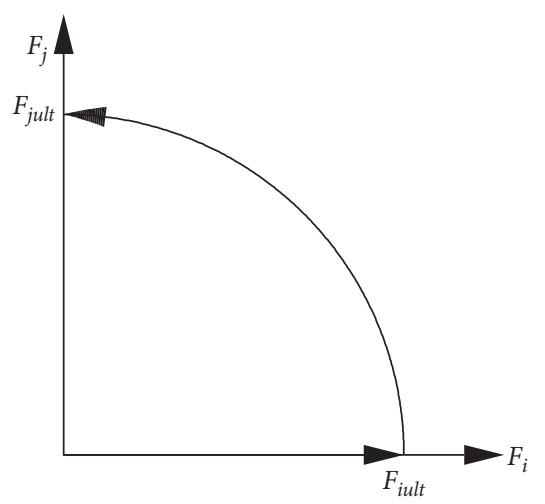

FIGURE 5: Diagram of the resulting envelope from displacementcontrolled swipe test.

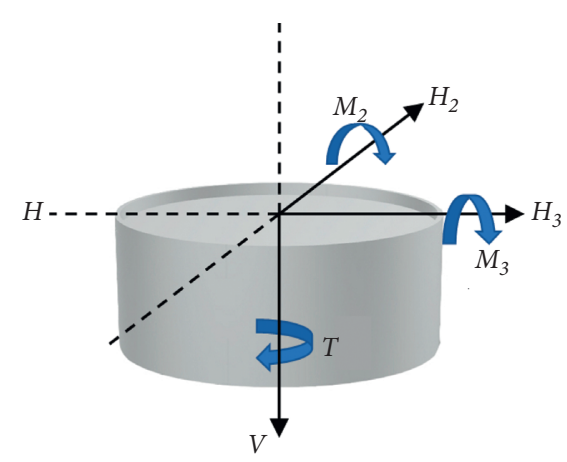

FiguRE 6: Sign conventions for the loads.

loading method was first obtained for scouring depths of $d / 12$, $d / 6$, and $d / 4$. The ultimate bearing capacity of the composite bucket foundation is shown in Table 1. It is apparent from Table 1 that the unidirectional ultimate bearing capacity decreases with increasing scour depth under the same vertical load. For the same scouring depth, the unidirectional ultimate bearing capacity of the horizontal load, torque, and bending moment show a trend of increasing initially and then decreasing with increasing the vertical load. This feature can be fully applied in the project to increase the vertical load appropriately, which is beneficial to offset the impact of scouring on the stability of the foundation.

3.2. Effect of Scouring Depth on the Load-Bearing Characteristics of $V$-H-T Combined Loading. In harsh marine environments, the torque loads from the superstructure of

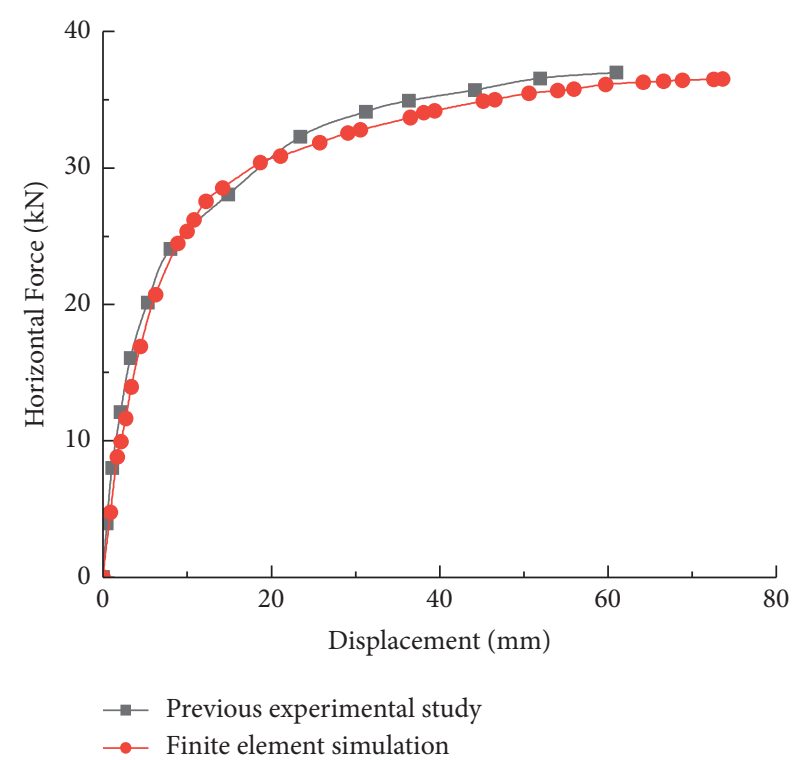

Figure 7: Load-displacement curve of the bucket foundation.

offshore wind turbines are often neglected in previous studies, which has a significant impact on the bearing capability of the foundation. Therefore, it is necessary to study the combined loads containing torque loads. In this section, the failure envelope of the combined $V-H-T$ load is analyzed considering the scouring effects.

The failure envelopes obtained are shown in Figure 8, which are represented by the $H-T$ failure envelopes at different vertical load levels $v\left(V / V_{\text {ult }}\right)$. It can be seen that the torque $T$ and horizontal load $H$ have decreasing effects on each other for a certain scouring depth and vertical load ratio. Moreover, with increasing the values of torque $T$ and horizontal load $H$, the decreasing effect increases dramatically. In addition, the $H$ - $T$ failure envelope under different vertical loads $V$ shrinks inward with increasing scour depth $S_{\mathrm{d}}$. This indicates that scouring has an adverse effect on the bearing capacity of the bucket foundation. The performance of the bucket foundation to resist the combined load of torque and horizontal load decreases, and safety and stability become poor.

To further analyze the effect of scouring depth on the $V$ $H$ - $T$ bearing capability, a normalized $V$ - $H$ - $T$ failure envelope at different scouring depths is conducted, as shown in Figure 9. As can be seen in Figure 9, the failure envelope of the bucket foundation gradually shrinks inwards as the scour depth increases, which indicates that the scour depth has a specific influence on the shape of the failure envelope. Therefore, it is necessary to adopt a series of measures to reduce the impact of scouring, which can significantly improve the stability of the composite bucket foundation. By fitting the curves in Figure 9, the $\mathrm{V}-\mathrm{H}-\mathrm{T}$ failure envelope equation at different scour depths is written in (1), which can be adopted to forecast the bearing ability of the composite bucket foundation under the combining loads $V-H-T$ with a certain scour depth. The relevant parameters are listed in Table 2. 
TABLE 1: Unidirectional ultimate bearing capacity of a composite bucket foundation.

\begin{tabular}{|c|c|c|c|c|c|c|c|c|c|}
\hline \multirow{2}{*}{$S_{\mathrm{d}}$} & \multicolumn{3}{|c|}{$V / V_{\text {ult }}=0.25$} & \multicolumn{3}{|c|}{$V / V_{\text {ult }}=0.50$} & \multicolumn{3}{|c|}{$V / V_{\text {ult }}=0.75$} \\
\hline & $H_{\text {ult }}(\mathrm{MN})$ & $M_{\mathrm{ult}}(\mathrm{MN} \cdot \mathrm{m})$ & $T_{\mathrm{ult}}(\mathrm{MN} \cdot \mathrm{m})$ & $H_{\text {ult }}(\mathrm{MN})$ & $M_{\mathrm{ult}}(\mathrm{MN} \cdot \mathrm{m})$ & $T_{\text {ult }}(\mathrm{MN} \cdot \mathrm{m})$ & $H_{\text {ult }}(\mathrm{MN})$ & $M_{\mathrm{ult}}(\mathrm{MN} \cdot \mathrm{m})$ & $T_{\mathrm{ult}}(\mathrm{MN} \cdot \mathrm{m})$ \\
\hline No scouring & 74.47 & 1027.56 & 577.75 & 80.11 & 1075.79 & 613.14 & 77.72 & 1057.56 & 615.02 \\
\hline$d / 12$ & 72.43 & 986.69 & 550.42 & 78.60 & 1046.01 & 583.74 & 76.99 & 1018.31 & 580.14 \\
\hline$d / 6$ & 67.00 & 955.69 & 529.19 & 72.88 & 1007.20 & 561.17 & 72.38 & 970.69 & 559.24 \\
\hline$d / 4$ & 59.14 & 919.55 & 503.17 & 65.03 & 961.14 & 531.39 & 63.45 & 861.25 & 521.49 \\
\hline
\end{tabular}

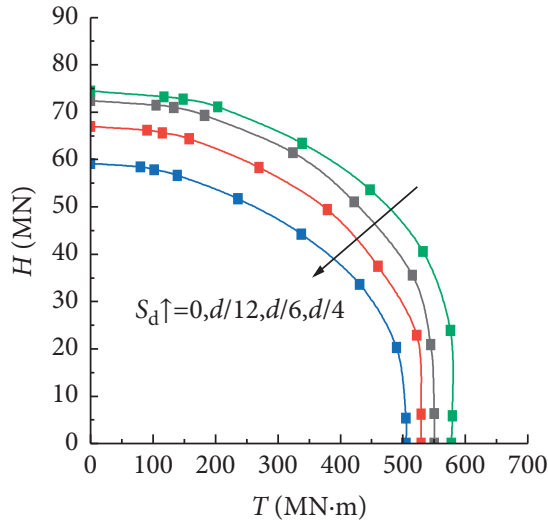

$\rightarrow$ No Scouring $\rightarrow S_{\mathrm{d}}=d / 6$
$\rightarrow S_{\mathrm{d}}=d / 12 \longrightarrow S_{\mathrm{d}}=d / 4$

(a)

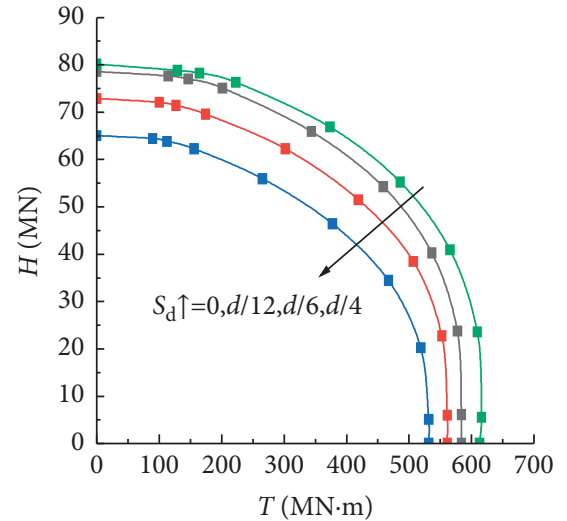

$\because$ No Scouring $\rightarrow-S_{\mathrm{d}}=d / 6$

$\rightarrow S_{\mathrm{d}}=d / 12 \rightarrow S_{\mathrm{d}}=d / 4$

(b)

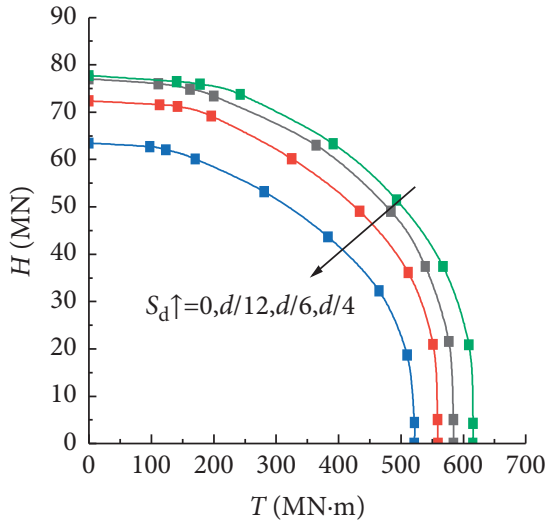

- No Scouring $\square-S_{\mathrm{d}}=d / 6$

$\rightarrow S_{\mathrm{d}}=d / 12 \rightarrow S_{\mathrm{d}}=d / 4$

(c)

FIgURE 8: $V-H$-T failure envelope at different scouring depths. (a) $v=0.25$. (b) $v=0.50$. (c) $v=0.75$.
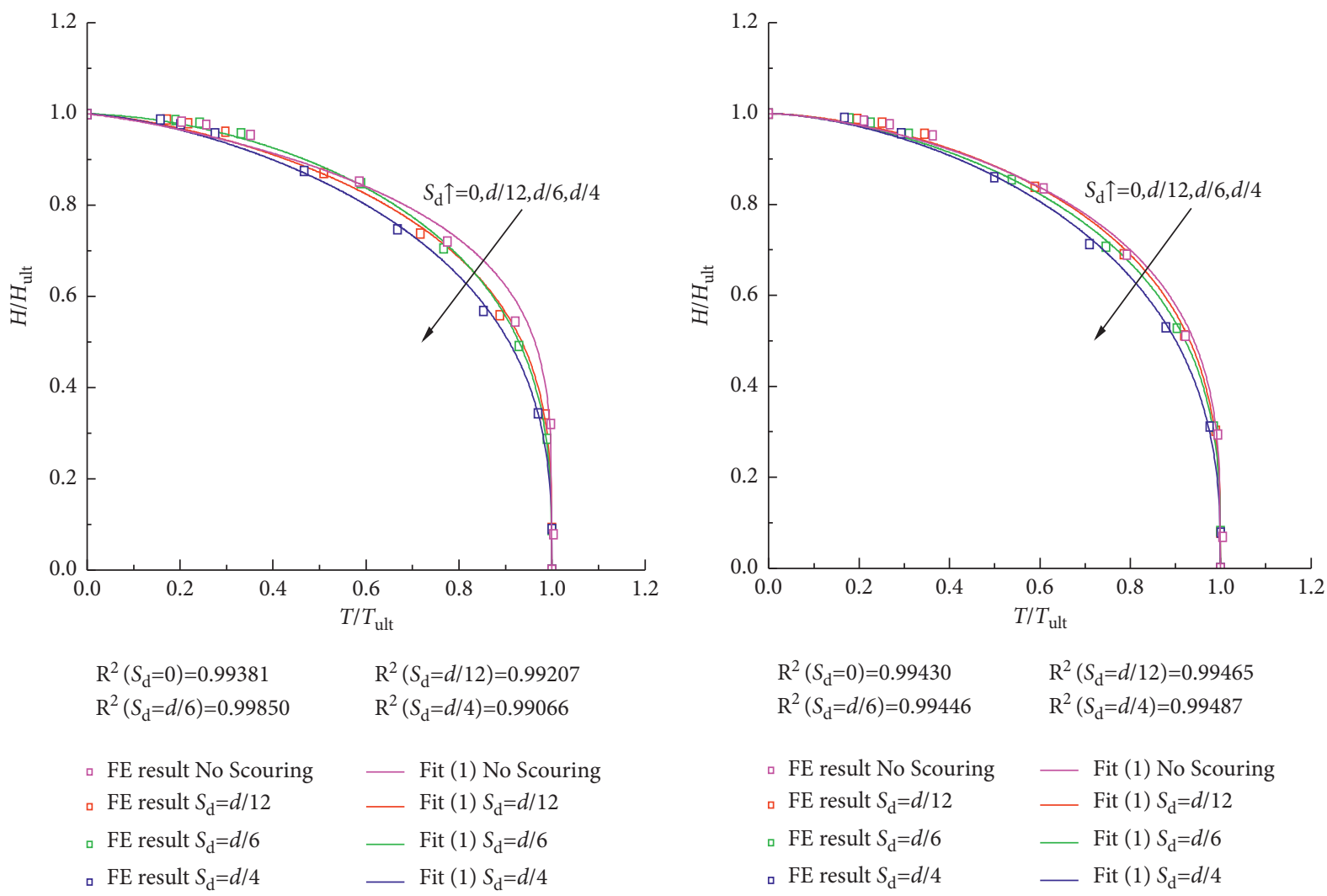

(a)

$$
\begin{array}{ll}
\mathrm{R}^{2}\left(S_{\mathrm{d}}=0\right)=0.99430 & \mathrm{R}^{2}\left(S_{\mathrm{d}}=d / 12\right)=0.99465 \\
\mathrm{R}^{2}\left(S_{\mathrm{d}}=d / 6\right)=0.99446 & \mathrm{R}^{2}\left(S_{\mathrm{d}}=d / 4\right)=0.99487 \\
& \\
\text { a FE result No Scouring } & - \text { Fit }(1) \text { No Scouring } \\
\text { a FE result } S_{\mathrm{d}}=d / 12 & - \text { Fit }(1) S_{\mathrm{d}}=d / 12 \\
\text { ․ FE result } S_{\mathrm{d}}=d / 6 & - \text { Fit }(1) S_{\mathrm{d}}=d / 6 \\
\text { - FE result } S_{\mathrm{d}}=d / 4 & \text { Fit }(1) S_{\mathrm{d}}=d / 4
\end{array}
$$

(b)

Figure 9: Continued. 


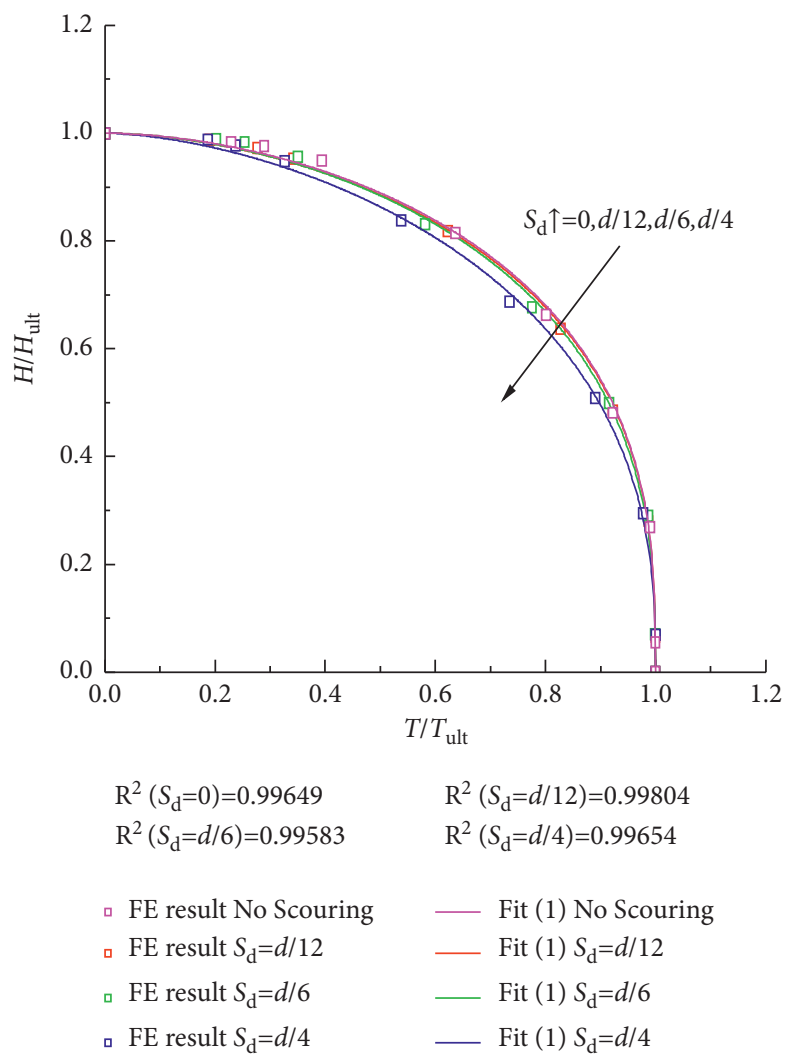

(c)

Figure 9: Normalized $V-H$-T failure envelope at different scouring depths. (a) $v=0.25$. (b) $v=0.50$. (c) $v=0.75$.

TABLE 2: Values of parameters $a$ and $b$.

\begin{tabular}{lcccccc}
\hline$S_{\mathrm{d}}$ & \multicolumn{2}{c}{$V / V_{\text {ult }}=0.25$} & \multicolumn{2}{c}{$V / V_{\text {ult }}=0.50$} & \multicolumn{2}{c}{$V / V_{\text {ult }}=0.75$} \\
& $a$ & $b$ & $a$ & $b$ & $a$ \\
\hline No scouring & 1.20 & 0.22 & 1.51 & 0.28 & 1.80 \\
$d / 12$ & 1.69 & 0.32 & 1.62 & 0.31 & 0.34 \\
$d / 6$ & 1.40 & 0.29 & 1.56 & 0.33 & 1.76 \\
$d / 4$ & 1.44 & 0.34 & 1.60 & 0.37 & 0.35 \\
\hline
\end{tabular}

$$
\frac{H}{H_{\mathrm{ult}}}=\left[1-\left(\frac{T}{T_{\mathrm{ult}}}\right)^{a}\right]^{b}
$$

where $H_{\text {ult }}$ and $T_{\text {ult }}$ are the ultimate horizontal bearing capacity and the ultimate torque bearing capacity under different vertical loads. The values of $H_{\text {ult }}$ and $T_{\text {ult }}$ can be obtained from Table 1 .

3.3. Effect of Scouring Depth on the Load-Bearing Characteristics of $V-M-T$ Combined Loading. Figure 10 shows the $V-M-T$ failure envelopes at different scour depths. A comparative analysis shows that when the torque is below $30 \%$ of the maximum ultimate torque, the ultimate bending moment remains unchanged. When the torque exceeds $180 \mathrm{MN} \cdot \mathrm{m}$, the ultimate bending moment decreases rapidly as the torque increases, and the coupling effect of torque and bending moment cannot be ignored at this time. Beyond that, the $V-M-T$ failure envelope shrinks inwards with increasing scour depth $S_{\mathrm{d}}$. The ultimate bending moment is also gradually reduced, indicating that the loadbearing capacity of the bucket foundation resistance to the combined moment and torque loads decreased as the scour depth increased under $V-M-T$ combined loading. The safety and stability of the bucket foundation are progressively reduced.

Figure 11 shows that the normalized $V-M-T$ failure envelopes of the bucket foundation at different scour depths almost coincide with good normalization under the condition of a certain vertical load level $v\left(V / V_{\text {ult }}\right)$. This indicates that while an increase in the scour depth is detrimental to the resistance of the bucket foundation with the combination of vertical load, moment load, and 


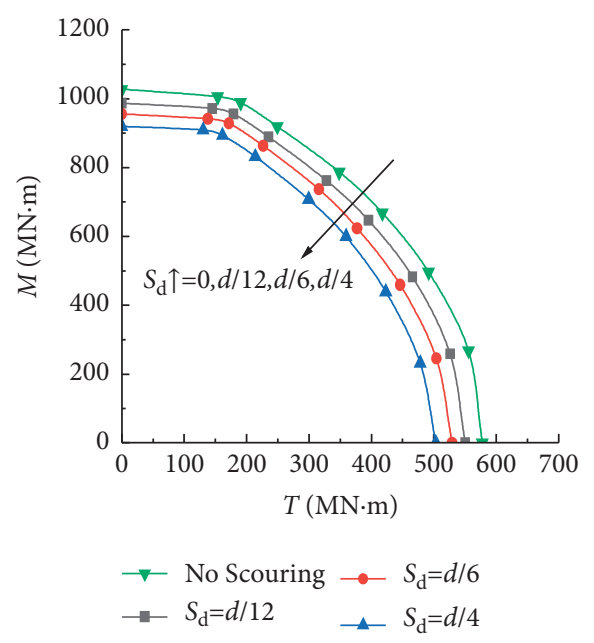

(a)

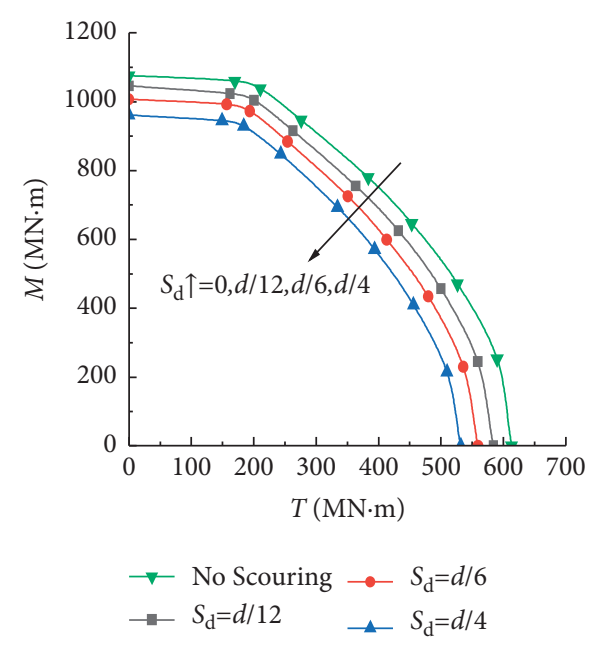

(b)

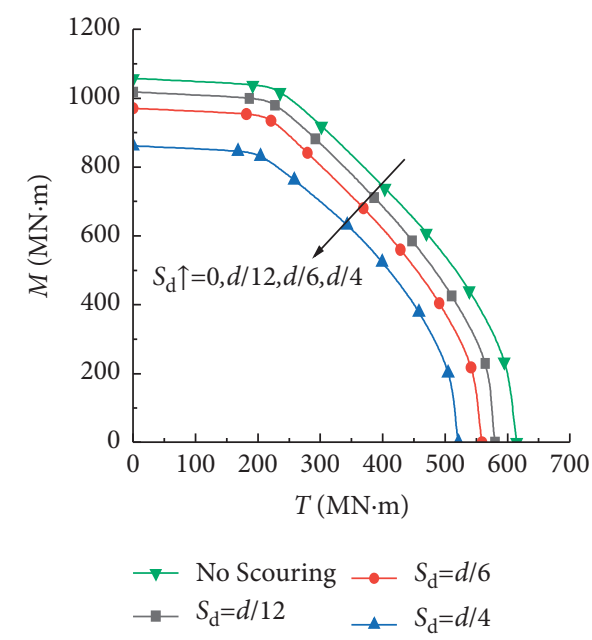

(c)

Figure 10: $V-M-T$ failure envelope at different scouring depths. (a) $v=0.25$. (b) $v=0.50$. (c) $v=0.75$.

torque load, it has few effects on the shape of the $V-M-T$ failure envelope. Such a characteristic is different from the $V-H-T$ failure envelope of the bucket foundation shown in Figure 9, which is consistent with the published results.

Comparing the results of FEA modeling, equation (2) is applied to determine the fitting expression of the $V-M-T$ failure envelope of the bucket foundation, where $M_{\text {ult }}$ is the ultimate bending moment of the bucket foundation under vertical loading, and the values of $M_{\text {ult }}$ can be obtained from Table 1 . The related parameters are taken as shown in Table 3.

$$
\frac{M}{M_{\mathrm{ult}}}=\left[1-\left(\frac{T}{T_{\mathrm{ult}}}\right)^{a}\right]^{b}
$$

From Table 3, one can find that the values of the formula parameters are very close to each other, with the magnitude of the difference almost always within $10 \%$. It indicates that the scour depth and vertical load level have little effect on the shape of the $V-M-T$ failure envelope. Therefore, a unified fitting equation is given for describing the $V-M-T$ failure envelope as

$$
\frac{M}{M_{\mathrm{ult}}}=\left[1-\left(\frac{T}{T_{\mathrm{ult}}}\right)^{2.09}\right]^{0.58} .
$$

3.4. Effect of Scouring Depth on the Load-Bearing Characteristics of $V-H-M$ Combined Loading. The $V-H-M$ failure envelopes at different scour depths are obtained by variable proportional displacement loading, and the results are shown in Figure 12. Figure 12 shows that the $V-H-M$ failure envelope shows nonconformity in the first and second quadrants, and the combined bearing capacity in the first quadrant is significantly larger than that in the second quadrant. Due to the coupling effect between the loads, the combined bearing capacity of the bucket foundation under the joint action of the horizontal load $H$ and moment load $M$ is higher than the single horizontal bearing capacity and single moment bearing capacity of the composite bucket 

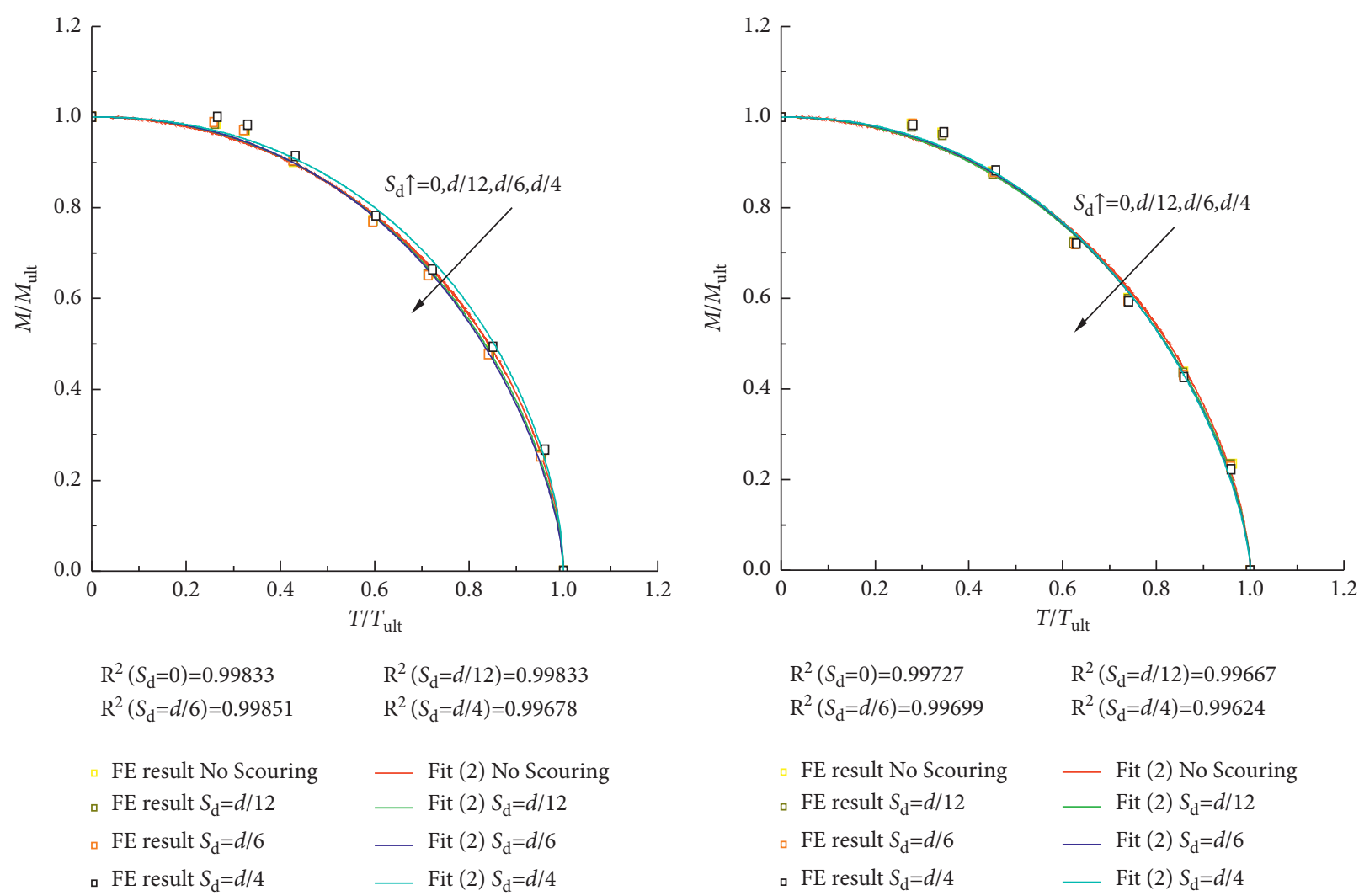
$\mathrm{R}^{2}\left(S_{\mathrm{d}}=0\right)=0.99833$
$\mathrm{R}^{2}\left(S_{\mathrm{d}}=d / 6\right)=0.99851$
$\mathrm{R}^{2}\left(S_{\mathrm{d}}=d / 12\right)=0.99833$
$\mathrm{R}^{2}\left(S_{\mathrm{d}}=d / 4\right)=0.99678$
FE result No Scouring
口 FE result $S_{\mathrm{d}}=d / 12$
口 FE result $S_{\mathrm{d}}=d / 6$
口 FE result $S_{\mathrm{d}}=d / 4$

$$
\begin{aligned}
& \text { — Fit (2) No Scouring } \\
& \text { Fit (2) } S_{\mathrm{d}}=d / 12 \\
& \text { — Fit (2) } S_{\mathrm{d}}=d / 6 \\
& \text { Fit (2) } S_{\mathrm{d}}=d / 4
\end{aligned}
$$

(a)

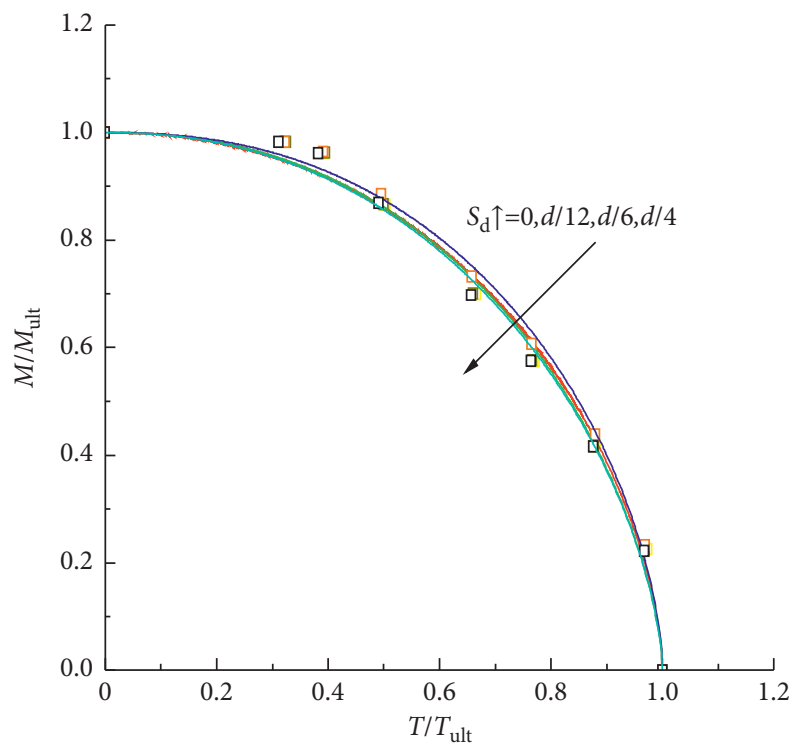

(b) 
TABLE 3: Values of parameters $a$ and $b$.

\begin{tabular}{lcccccc}
\hline$S_{\mathrm{d}}$ & \multicolumn{2}{c}{$V / V_{\text {ult }}=0.25$} & \multicolumn{2}{c}{$V / V_{\text {ult }}=0.50$} & \multicolumn{2}{c}{$V / V_{\text {ult }}=0.75$} \\
& $a$ & $b$ & $a$ & $b$ & $a$ \\
\hline No scouring & 2.21 & 0.57 & 2.06 & 0.62 & 2.19 \\
$d / 12$ & 2.09 & 0.58 & 2.07 & 0.63 & 0.63 \\
$d / 6$ & 2.17 & 0.62 & 2.17 & 0.66 & 0.60 \\
$d / 4$ & 2.21 & 0.63 & 2.19 & 0.67 & 2.24 \\
\end{tabular}

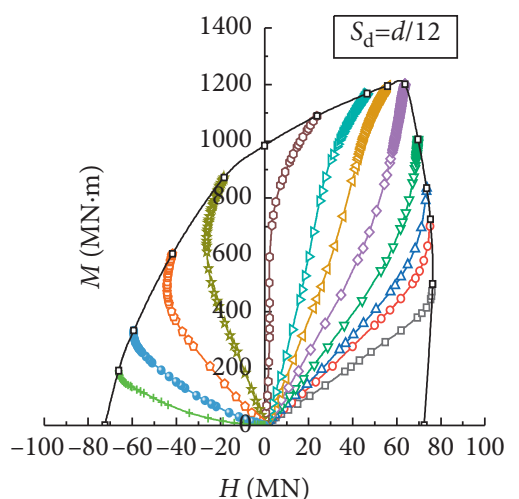

$$
\begin{array}{ll}
\rightarrow u / \theta_{\mathrm{m}}=40 & \rightarrow u / \theta_{\mathrm{m}}=1 \\
\multimap u / \theta_{\mathrm{m}}=20 & \rightarrow u / \theta_{\mathrm{m}}=-1 \\
\neg u / \theta_{\mathrm{m}}=15 & \rightarrow u / \theta_{\mathrm{m}}=-6 \\
\multimap-u / \theta_{\mathrm{m}}=10 & \multimap u / \theta_{\mathrm{m}}=-10 \\
\multimap u / \theta_{\mathrm{m}}=6 & \rightarrow u / \theta_{\mathrm{m}}=-15 \\
\neg u / \theta_{\mathrm{m}}=3 & \multimap u / \theta_{\mathrm{m}}=-20
\end{array}
$$

(a)

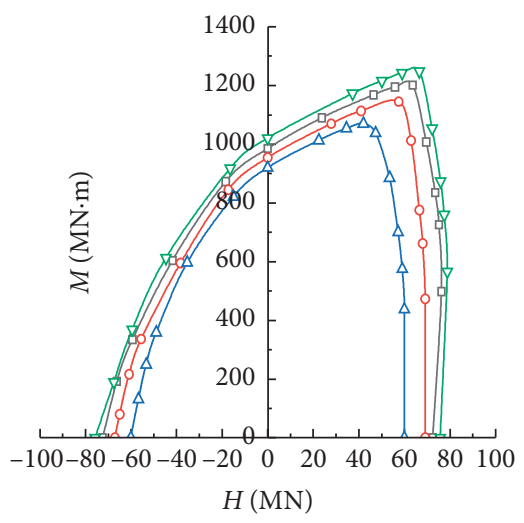

$$
\begin{array}{ll}
\rightarrow-\text { No Scouring } & \multimap \\
\neg-S_{\mathrm{d}}=d / 6 \\
& \rightarrow S_{\mathrm{d}}=d / 4
\end{array}
$$

(d)
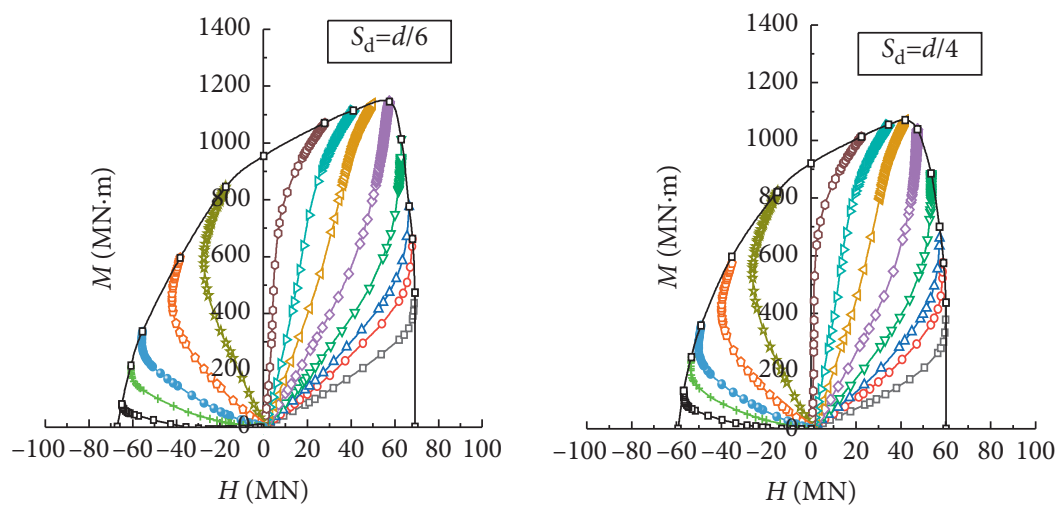

(b)

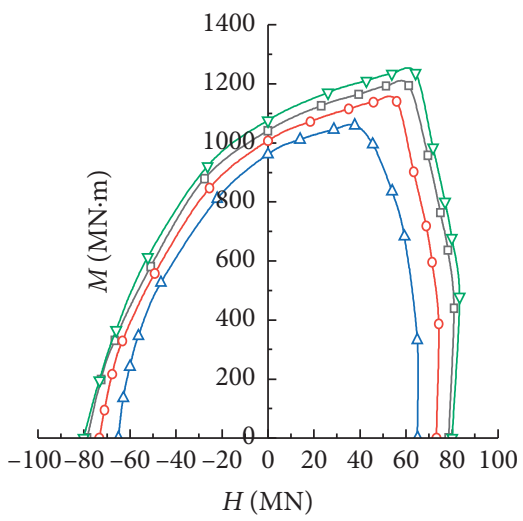

$\begin{array}{ll}\rightarrow-\text { No Scouring } & \rightarrow S_{\mathrm{d}}=d / 6 \\ \rightarrow-S_{\mathrm{d}}=d / 12 & \rightarrow-S_{\mathrm{d}}=d / 4\end{array}$

(e)

$$
\begin{aligned}
& \neg-u / \theta_{\mathrm{m}}=40 \quad \multimap-u / \theta_{\mathrm{m}}=-1 \\
& \multimap u / \theta_{\mathrm{m}}=20 \rightarrow u / \theta_{\mathrm{m}}=-6 \\
& \neg-u / \theta_{\mathrm{m}}=15 \quad \neg u / \theta_{\mathrm{m}}=-10 \\
& \rightarrow u / \theta_{\mathrm{m}}=10 \quad \multimap u / \theta_{\mathrm{m}}=-15 \\
& \neg u / \theta_{\mathrm{m}}=6 \quad \rightarrow u / \theta_{\mathrm{m}}=-20 \\
& \neg u / \theta_{\mathrm{m}}=3 \quad \square u / \theta_{\mathrm{m}}=-30 \\
& \rightarrow u / \theta_{\mathrm{m}}=1
\end{aligned}
$$

(c)

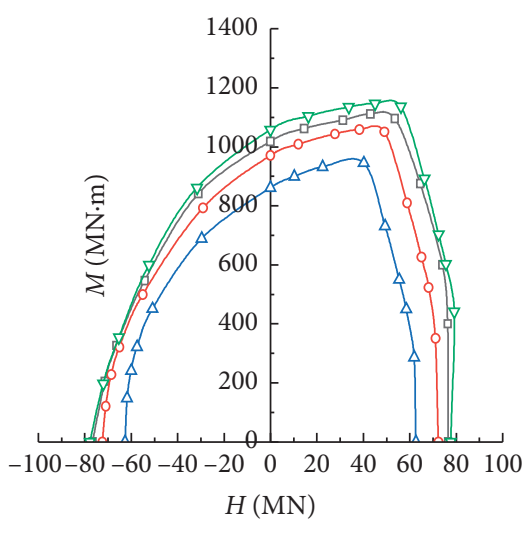

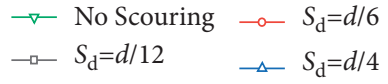

(f)

Figure 12: $V-H-M$ failure envelope at different scouring depths. (a) $v=0.25 S_{\mathrm{d}}=d / 12$. (b) $v=0.25 S_{\mathrm{d}}=d / 6$. (c) $v=0.25 S_{\mathrm{d}}=d / 4$. (d) $v=0.25$. (e) $v=0.50$. (f) $v=0.75$. 

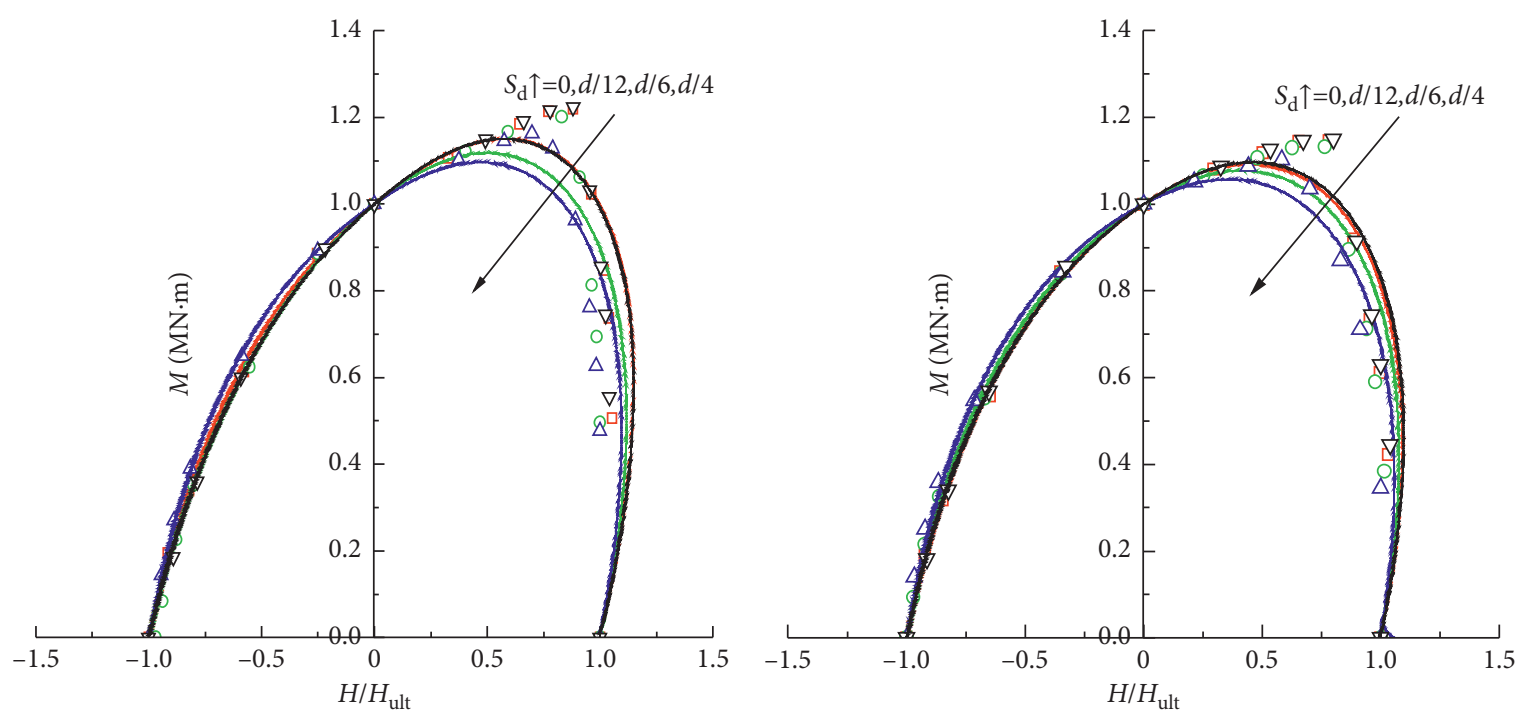

$$
\mathrm{R}^{2}\left(S_{\mathrm{d}}=0\right)=0.99635
$$$$
\mathrm{R}^{2}\left(S_{\mathrm{d}}=d / 12\right)=0.99560
$$$$
\mathrm{R}^{2}\left(S_{\mathrm{d}}=d / 4\right)=0.99559
$$

$\mathrm{R}^{2}\left(S_{\mathrm{d}}=0\right)=0.99700$

$\mathrm{R}^{2}\left(S_{\mathrm{d}}=d / 6\right)=0.99877$

$\nabla$ FE result No Scouring

- FE result $S_{\mathrm{d}}=d / 12$

- FE result $S_{\mathrm{d}}=d / 6$

$\Delta$ FE result $S_{\mathrm{d}}=d / 4$

(a)

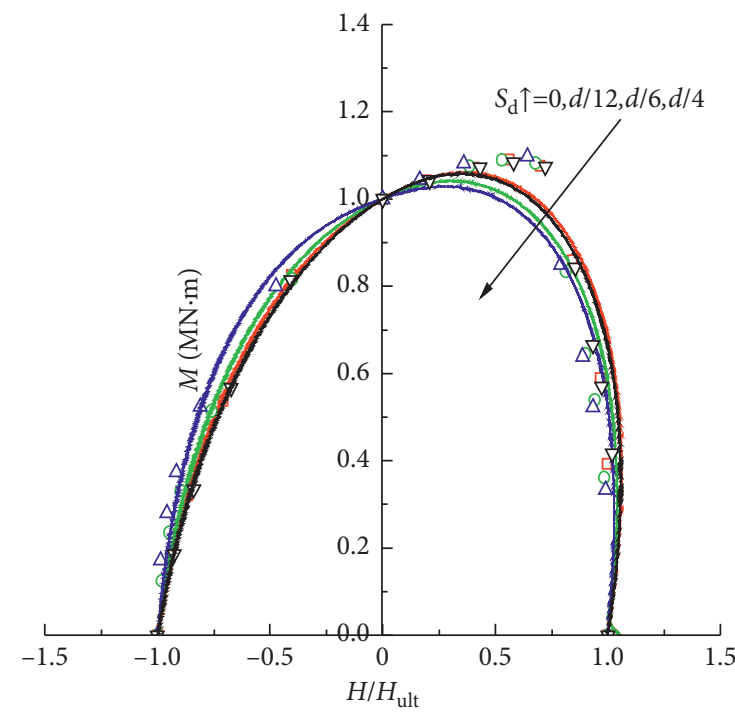

$$
\begin{aligned}
& \mathrm{R}^{2}\left(S_{\mathrm{d}}=0\right)=0.99850 \\
& \mathrm{R}^{2}\left(S_{\mathrm{d}}=d / 12\right)=0.99760 \\
& \mathrm{R}^{2}\left(S_{\mathrm{d}}=d / 6\right)=0.99758 \\
& \mathrm{R}^{2}\left(S_{\mathrm{d}}=d / 4\right)=0.99828
\end{aligned}
$$

$\mathrm{R}^{2}\left(S_{\mathrm{d}}=d / 12\right)=0.99726$

$\mathrm{R}^{2}\left(S_{\mathrm{d}}=d / 4\right)=0.99698$

__ Fit (4) No Scouring

- Fit (4) $S_{\mathrm{d}}=d / 12$

— Fit (4) $S_{\mathrm{d}}=d / 6$

- Fit (4) $S_{\mathrm{d}}=d / 4$

(b) 
TABle 4: Values of parameters $\alpha$ and $\beta$.

\begin{tabular}{lcccccc}
\hline$S_{\mathrm{d}}$ & \multicolumn{2}{c}{$V / V_{\text {ult }}=0.25$} & \multicolumn{2}{c}{$V / V_{\text {ult }}=0.50$} & \multicolumn{2}{c}{$V / V_{\text {ult }}=0.75$} \\
& $\alpha$ & $\beta$ & $\alpha$ & $\beta$ & $\alpha$ \\
\hline No scouring & 2.17 & 0.49 & 2.16 & 0.40 & 2.07 \\
$d / 12$ & 2.29 & 0.50 & 2.14 & 0.39 & 0.32 \\
$d / 6$ & 2.06 & 0.44 & 2.16 & 0.36 & 2.16 \\
$d / 4$ & 2.26 & 0.40 & 2.19 & 0.31 & 0.32 \\
\end{tabular}

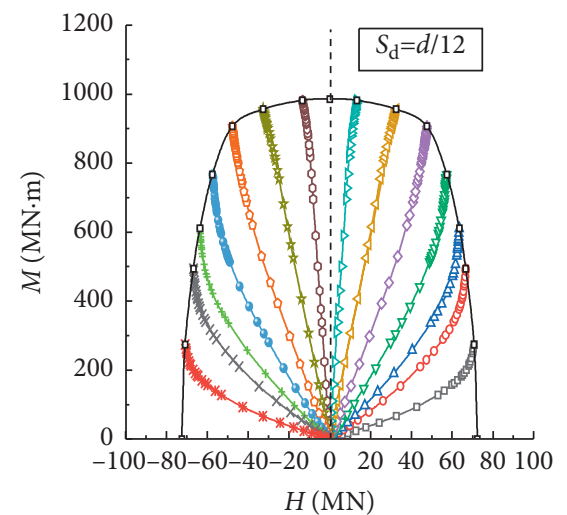

$$
\begin{aligned}
& \neg-u / \theta_{\mathrm{m}}=40 \quad-0-u / \theta_{\mathrm{m}}=-1 \\
& \multimap u / \theta_{\mathrm{m}}=20 \rightarrow u / \theta_{\mathrm{m}}=-3 \\
& \neg u / \theta_{\mathrm{m}}=15 \rightarrow u / \theta_{\mathrm{m}}=-6 \\
& \rightarrow-u / \theta_{\mathrm{m}}=10 \rightarrow u / \theta_{\mathrm{m}}=-10 \\
& \neg u / \theta_{\mathrm{m}}=6 \longrightarrow u / \theta_{\mathrm{m}}=-15 \\
& \neg u / \theta_{\mathrm{m}}=3 \rightarrow u / \theta_{\mathrm{m}}=-20 \\
& \rightarrow u / \theta_{\mathrm{m}}=1 \rightarrow u / \theta_{\mathrm{m}}=-40
\end{aligned}
$$

(a)
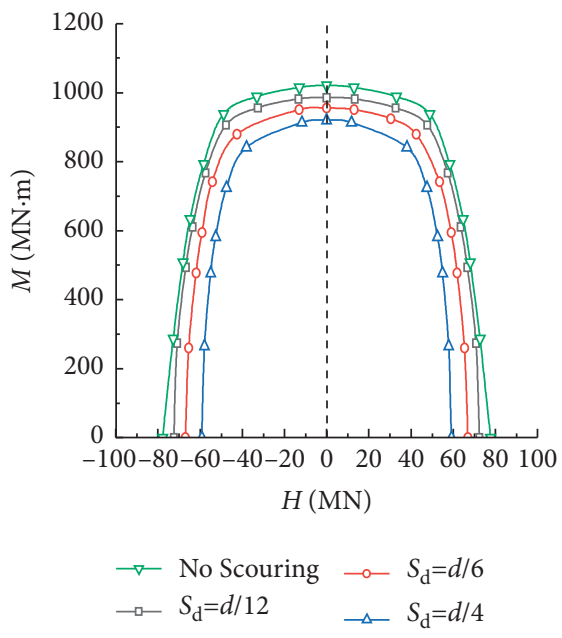

(d)

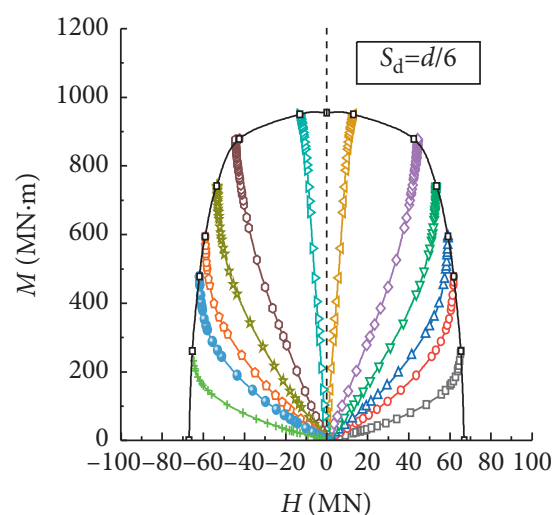

$$
\begin{array}{ll}
\rightarrow u / \theta_{\mathrm{m}}=40 & \rightarrow u / \theta_{\mathrm{m}}=-1 \\
\multimap u / \theta_{\mathrm{m}}=20 & \rightarrow u / \theta_{\mathrm{m}}=-6 \\
\rightarrow-u / \theta_{\mathrm{m}}=15 & \rightarrow u u / \theta_{\mathrm{m}}=-10 \\
\rightarrow u / \theta_{\mathrm{m}}=10 & \multimap u / \theta_{\mathrm{m}}=-15 \\
\multimap u / \theta_{\mathrm{m}}=6 & \rightarrow u / \theta_{\mathrm{m}}=-20 \\
\neg u / \theta_{\mathrm{m}}=1 & \rightarrow u / \theta_{\mathrm{m}}=-40
\end{array}
$$

(b)

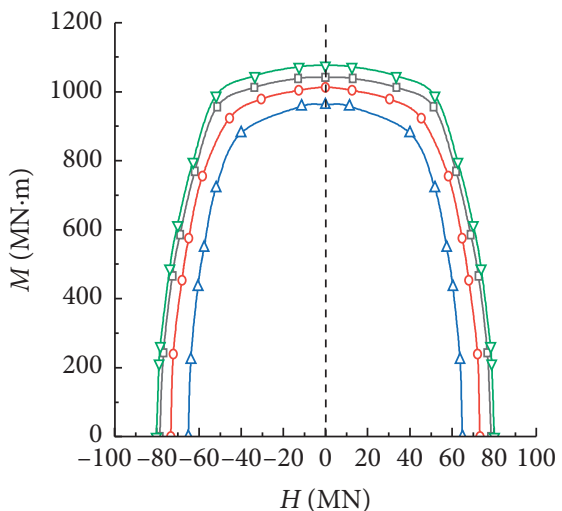

$\begin{array}{ll}\rightarrow-\text { No Scouring } & \rightarrow S_{\mathrm{d}}=d / 6 \\ \rightarrow S_{\mathrm{d}}=d / 12 & \rightarrow S_{\mathrm{d}}=d / 4\end{array}$

(e)

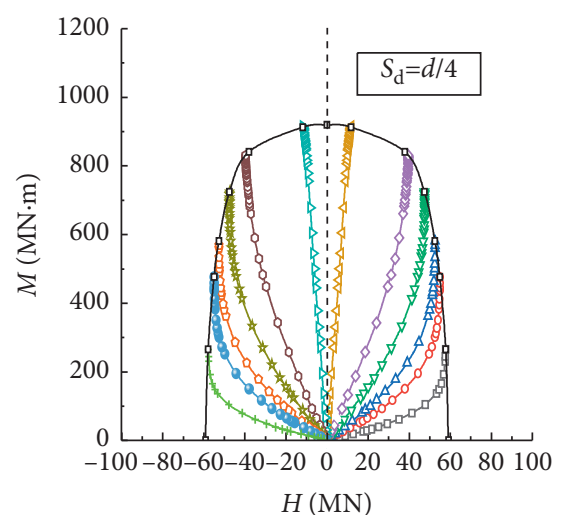

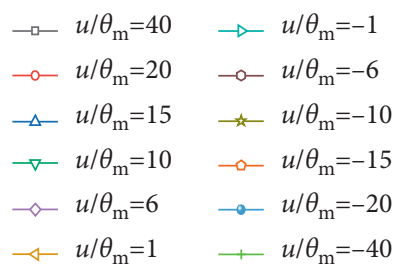

(c)

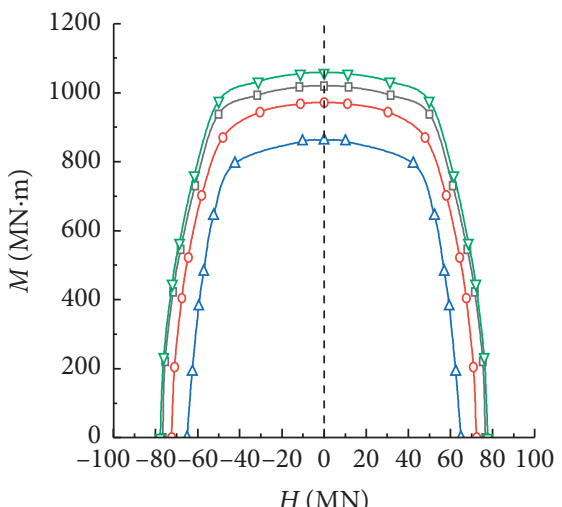

$\rightarrow-$ No Scouring $\multimap S_{\mathrm{d}}=d / 6$

$\rightarrow S_{\mathrm{d}}=d / 12 \quad \rightarrow S_{\mathrm{d}}=d / 4$

(f)

FIGURE 14: Noncoplanar $V-H-M$ failure envelope at different scouring depths. (a) $v=0.25 S_{\mathrm{d}}=d / 12$. (b) $v=0.25 S_{\mathrm{d}}=d / 6$. (c) $v=0.25 S_{\mathrm{d}}=d / 4$. (d) $v=0.25$. (e) $v=0.50$. (f) $v=0.75$. 

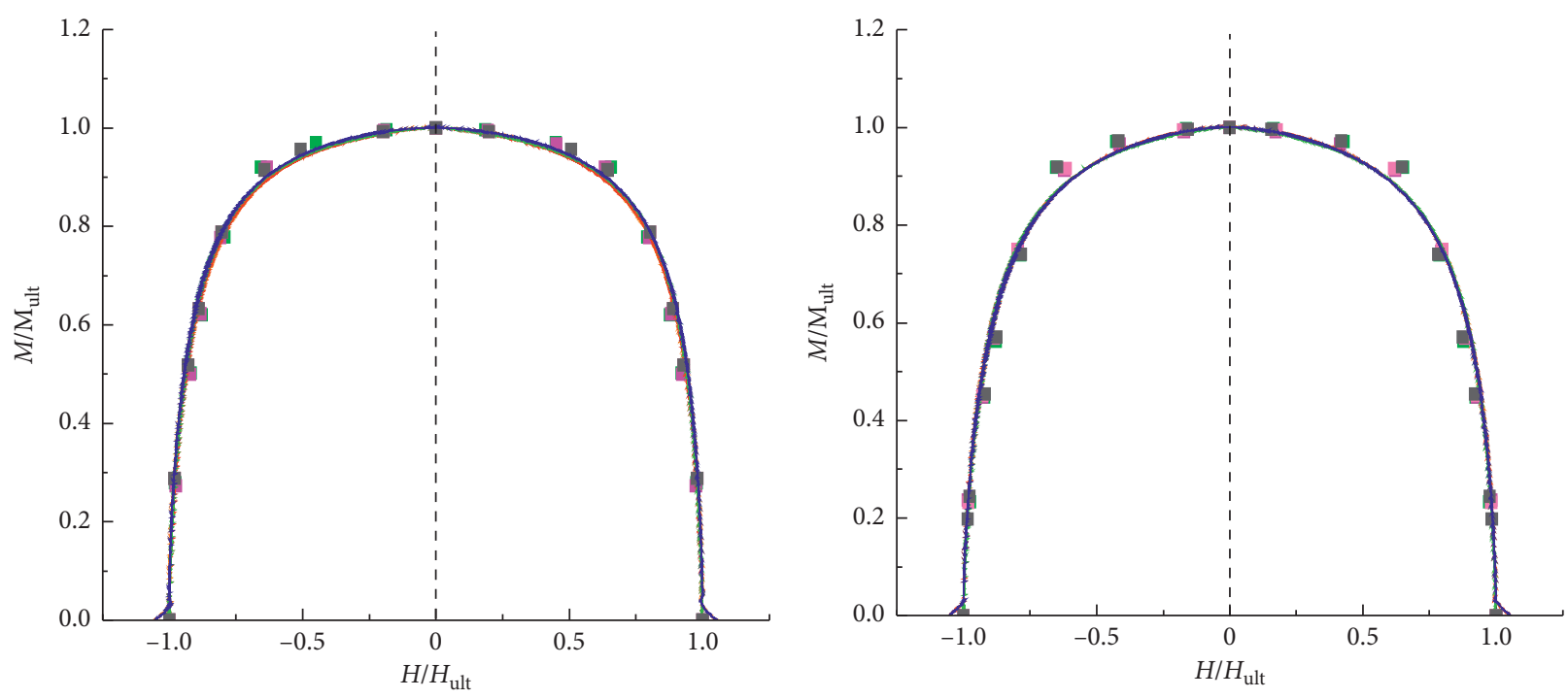

$$
\begin{array}{ll}
\mathrm{R}^{2}\left(S_{\mathrm{d}}=0\right)=0.99971 & \mathrm{R}^{2}\left(S_{\mathrm{d}}=d / 12\right)=0.99982 \\
\mathrm{R}^{2}\left(S_{\mathrm{d}}=d / 6\right)=0.99993 & \mathrm{R}^{2}\left(S_{\mathrm{d}}=d / 4\right)=0.99991 \\
\text { - FE result No Scouring } & - \text { Fit }(5) \text { No Scouring } \\
\text { - FE result } S_{\mathrm{d}}=d / 12 & - \text { Fit }(5) S_{\mathrm{d}}=d / 12 \\
\text { - FE result } S_{\mathrm{d}}=d / 6 & - \text { Fit }(5) S_{\mathrm{d}}=d / 6 \\
\text { - FE result } S_{\mathrm{d}}=d / 4 & \text { - Fit }(5) S_{\mathrm{d}}=d / 4
\end{array}
$$

— Fit (5) No Scouring
Fit (5) $S_{\mathrm{d}}=d / 12$
Fit (5) $S_{\mathrm{d}}=d / 6$
Fit (5) $S_{\mathrm{d}}=d / 4$

(a)

$$
\begin{array}{ll}
\mathrm{R}^{2}\left(S_{\mathrm{d}}=0\right)=0.99945 & \mathrm{R}^{2}\left(S_{\mathrm{d}}=d / 12\right)=0.99945 \\
\mathrm{R}^{2}\left(S_{\mathrm{d}}=d / 6\right)=0.99980 & \mathrm{R}^{2}\left(S_{\mathrm{d}}=d / 4\right)=0.99981 \\
\text { - FE result No Scouring } & - \text { Fit (5) No Scourin } \\
\text { - FE result } S_{\mathrm{d}}=d / 12 & - \text { Fit }(5) S_{\mathrm{d}}=d / 12 \\
\text { - FE result } S_{\mathrm{d}}=d / 6 & - \text { Fit (5) } S_{\mathrm{d}}=d / 6 \\
\text { - FE result } S_{\mathrm{d}}=d / 4 & - \text { Fit (5) } S_{\mathrm{d}}=d / 4
\end{array}
$$

(b)

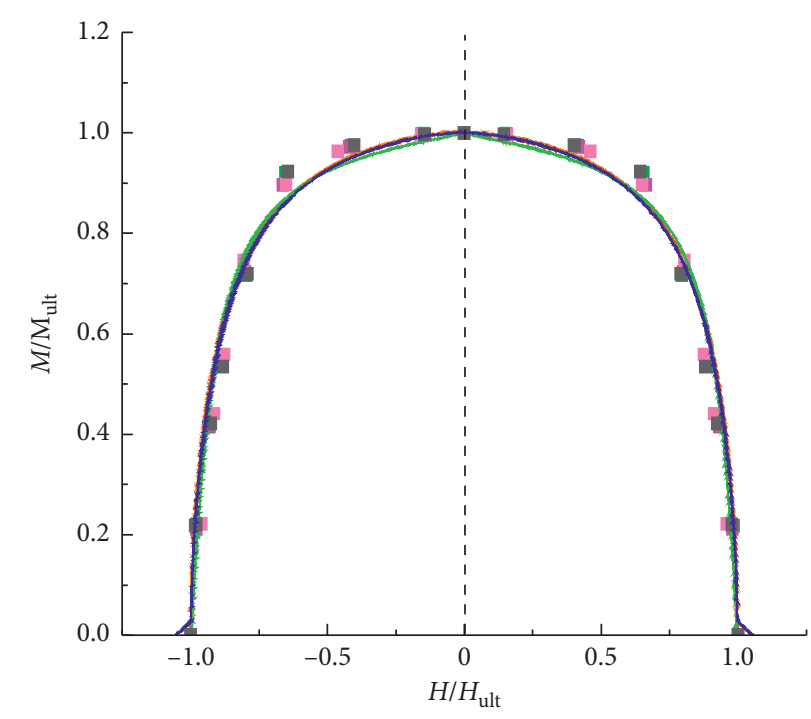

$$
\begin{array}{ll}
\mathrm{R}^{2}\left(S_{\mathrm{d}}=0\right)=0.99955 & \mathrm{R}^{2}\left(S_{\mathrm{d}}=d / 12\right)=0.99942 \\
\mathrm{R}^{2}\left(S_{\mathrm{d}}=d / 6\right)=0.99965 & \mathrm{R}^{2}\left(S_{\mathrm{d}}=d / 4\right)=0.99959 \\
\text { - FE result No Scouring } & - \text { Fit (5) No Scouring } \\
\text { - FE result } S_{\mathrm{d}}=d / 12 & - \text { Fit }(5) S_{\mathrm{d}}=d / 12 \\
\text { - FE result } S_{\mathrm{d}}=d / 6 & \text { - Fit }(5) S_{\mathrm{d}}=d / 6 \\
\text { - FE result } S_{\mathrm{d}}=d / 4 & \text { - Fit (5) } S_{\mathrm{d}}=d / 4
\end{array}
$$

(c)

FIGURE 15: Normalized noncoplanar $V-H-M$ failure envelope at different scouring depths. (a) $v=0.25$. (b) $v=0.50$. (c) $v=0.75$. 
TABLe 5: Values of parameters $\alpha$ and $\beta$.

\begin{tabular}{lcccccc}
\hline \multirow{2}{*}{$S_{\mathrm{d}}$} & \multicolumn{2}{c}{$V / V_{\text {ult }}=0.25$} & \multicolumn{2}{c}{$V / V_{\text {ult }}=0.50$} & \multicolumn{2}{c}{$V / V_{\text {ult }}=0.75$} \\
& $\alpha$ & $\beta$ & $\alpha$ & $\beta$ & $\alpha$ & $\beta$ \\
\hline No scouring & 1.03 & 0.46 & 1.02 & 0.45 & 1.03 & 0.45 \\
$d / 12$ & 1.04 & 0.45 & 1.03 & 0.45 & 1.04 & 0.44 \\
$d / 6$ & 1.02 & 0.46 & 1.04 & 0.45 & 1.03 & 0.45 \\
$d / 4$ & 1.02 & 0.45 & 1.02 & 0.45 & 0.98 & 0.47 \\
\hline
\end{tabular}

foundation. This characteristic is great for improving the load-bearing capacity of the composite bucket foundation.

Figure 13 shows that the normalized $V-H-M$ failure envelope of the bucket foundation in the first quadrant gradually shrinks inward and gradually expands outward in the second quadrant as scour depth increases. The asymmetry of the bucket foundation about the $M$-axis decreases gradually. Figure 13 illustrates that equation (4) proposed in this paper can fit the normalized $V-H-M$ failure envelope well, where $h=H / H_{\text {ult }}$ and $m=M / M_{\text {ult }}$. The values of the relevant parameters are taken in Table 4.

$$
|h|^{\alpha}+m^{\alpha}+2 \beta h m=1
$$

3.5. Effect of Scouring Depth on the Load-Bearing Characteristics of Noncoplanar V-H-M Combined Loading. Conventional coplanar $V-H-M$ combined loading is equivalent to $\mathrm{V}-\mathrm{H}_{3}-\mathrm{M}_{2}$ or $\mathrm{V}-\mathrm{H}_{2}-M_{3}$, which often ignores the special case of the $V-H_{3}-M_{3}$ or $V-H_{2}-M_{2}$ noncoplanar combined loading conditions. According to the symmetry of the load, the failure envelopes of $\mathrm{V}-\mathrm{H}_{3}-\mathrm{M}_{3}$ and $\mathrm{V}-\mathrm{H}_{2}-\mathrm{M}_{2}$ noncoplanar composite loading in three-dimensional space are fully consistent, so only $\mathrm{V}-\mathrm{H}_{3}-\mathrm{M}_{3}$ combined loading is studied in this paper. The failure envelopes of noncongruent $V-H-M$ combined loading at different scour depths are shown in Figure 14.

It is evident from Figure 14 that the noncoplanar $\mathrm{V}-\mathrm{H}$ $M$ failure envelope is symmetric about the $M$-axis in the first and second quadrants with excellent symmetry, which is significantly different from the conventional coplanar $V-H-M$ failure envelope. Compared with the conventional coplanar $V-H-M$ failure envelope, the combined bearing capacity of the noncoplanar $V-H-M$ failure envelope in the first quadrant is significantly lower than that of the conventional coplanar $V-H-M$ failure envelope, and the combined bearing capacity in the second quadrant is markedly higher than that of the conventional coplanar $V$ $H-M$ failure envelope. As the depth of the scouring increases, the vertical load has an increasing effect on the magnitude of the reduction in bearing capacity. Here is some reference for the design of materials for offshore wind turbines. In general, compared to conventional coplanar $V$ $H-M$ combined loading, noncoplanar $V-H-M$ combined loading is more detrimental to the stability of the bucket foundation.

It is evident from Figure 15 that the normalized noncoplanar $\mathrm{V}-\mathrm{H}-\mathrm{M}$ failure envelopes coincide with suitable normalization, indicating that the law of the scour depth effect on the noncoplanar combined $V-H-M$ bearing capacity of the composite bucket foundation is consistent, and the scour depth has few effects on the normalized failure envelopes. This is distinctly different from the conventional coplanar $\mathrm{V}-\mathrm{H}-\mathrm{M}$ normalized failure envelope properties. Figure 15 shows that equation (5) fits the normalized noncoplanar $V-H-M$ failure envelope very well where $h=H$ / $H_{\mathrm{ult}}$ and $m=M / M_{\mathrm{ult}}$, and the values of the relevant parameters are shown in Table 5.

$$
|h|^{\alpha}+m^{\alpha}-2 \beta|h| m=1 .
$$

A close approximation of the values of the formula parameters can be seen from Table 5, nearly always within $10 \%$ of the value of the difference. It indicates that the scour depth and vertical load level have little effect on the shape of the $V-H-M$ failure envelope. Therefore, a unified fitting equation for the $\mathrm{V}-\mathrm{H}-\mathrm{M}$ failure envelope is given as

$$
|h|^{1.04}+m^{1.04}-0.9|h| m=1 .
$$

\section{Conclusions}

In this study, a finite element model of the composite bucket foundation with a horseshoe-shaped scour pit is established. Based on the finite element model, the effect of the scour depth on the composite bearing capacity of the bucket foundation is numerically investigated. Moreover, equations are fitted to determine the shape of the failure envelope for the composite bucket foundation under different scour depths. According to the numerical results, some concluding remarks can be drawn as follows:

(1) The unidirectional ultimate bearing capacity decreases with increasing the scour depth. For the same scouring depth, the unidirectional ultimate bearing capacity increases first and then decreases with the increase of the vertical load level

(2) The trends of the $V-H$-T and $V-M-T$ failure envelope at different scouring depths are similar to each other. The failure envelope shrinks inwards with increasing the scour depth. As the torque exceeds $30 \%$ of the unidirectional torque bearing capacity, the bearing capacities of the horizontal and moment loads decrease sharply for increasing the torque load

(3) The noncoplanar $V-H-M$ failure envelope is symmetrical about the $M$-axis under different scour depths. Whether the horizontal and moment loads are in the first or second quadrant, the combined bearing capacity of the horizontal and moment loads is less than that of these two single loads

(4) Scour depth has a significant effect on the normalized $V-H-T$ and $V-H-M$ failure envelopes but little effect on the normalized $V-M-T$ and the noncoplanar $V-H-M$ failure envelopes. The normalized $V-H-T$ and $V-H-M$ failure envelopes in the first quadrant gradually shrink inward with the increase of the scour depth. The normalized $V-M-T$ and noncoplanar $V-H-M$ failure envelopes coincide almost exactly under different scour depths. 


\section{Data Availability}

The data used to endorse the conclusions of this paper are presented in tables and figures within the study.

\section{Conflicts of Interest}

The authors declare that there are no conflicts of interest regarding the publication of this study.

\section{Acknowledgments}

This research was supported by the Beijing Natural Science Foundation (JQ19029), National Key R\&D Program of China (2018YFC1504305), and National Natural Science Foundation of China (U1839201). The support is gratefully acknowledged.

\section{References}

[1] K.-Y. Oh, W. Nam, M. S. Ryu, J. Y. Kim, and B. I. Epureanu, "A review of foundations of offshore wind energy convertors: current status and future perspectives," Renewable and Sustainable Energy Reviews, vol. 88, pp. 16-36, 2018.

[2] Q. Wang, X. Han, Y. Guan, Y. Cao, and W. Li, "Evaluation of undrained bearing capacities of wide-Shallow bucket foundation with honeycomb bulkheads in Clay," Advances in Civil Engineering, vol. 2019, pp. 1-13, 2019.

[3] J. K. Kaldellis, D. Apostolou, M. Kapsali, and E. Kondili, "Environmental and social footprint of offshore wind energy. Comparison with onshore counterpart," Renewable Energy, vol. 92, pp. 543-556, 2016.

[4] X. Wang, X. Yang, and X. Zeng, "Centrifuge modeling of lateral bearing behavior of offshore wind turbine with suction bucket foundation in sand," Ocean Engineering, vol. 139, pp. 140-151, 2017.

[5] Y. Liu, Y. Guo, H. Ding, and P. Zhang, "Failure envelopes of wide-shallow composite bucket foundation for offshore wind turbines in silty sand," Transactions of Tianjin University, vol. 24, no. 2, pp. 182-190, 2018.

[6] J. Lian, F. Chen, and H. Wang, "Laboratory tests on soil-skirt interaction and penetration resistance of suction caissons during installation in sand," Ocean Engineering, vol. 84, pp. 1-13, 2014.

[7] P. Zhang, Y. Li, Y. Lv, H. Ding, and C. Le, "Bearing capacity characteristics of composite bucket foundation under torque loading," Energies, vol. 12, no. 13, 2019.

[8] S. Li, Y. Wang, Q. Li, J. Huang, and J. Li, "Failure envelopes of bucket foundations for offshore wind turbines under combined loading including torsion," KSCE Journal of Civil Engineering, vol. 23, no. 12, pp. 5154-5162, 2019.

[9] X. Zhao, P. Zhang, Y. Lv, and H. Ding, "Scour effects on bearing capacity of composite bucket foundation for offshore wind turbines," Marine Georesources and Geotechnology, vol. 38, no. 2, pp. 223-237, 2020.

[10] Z. Xiao, Y. Liu, B. Ge, D. Fu, Z. Zhou, and Y. Yan, "Bearing performance of offshore bucket foundation with internal cruciform skirt under combined loading," Marine Georesources and Geotechnology, vol. 38, no. 10, pp. 1209-1222, 2020.

[11] R. Liu, G. S. Chen, Y. C Liu, and Y. Xu, "Resisting moment behavior of large diameter and shallow buried bucket foundation for offshore wind turbine," Journal of Tianjin University, vol. 46, no. 5, pp. 393-400, 2013.

[12] R. Liu, G. Chen, J. Lian, and H. Ding, "Vertical bearing behaviour of the composite bucket shallow foundation of offshore wind turbines," Journal of Renewable and Sustainable Energy, vol. 7, no. 1, Article ID 013123, 2015.

[13] Y. G. Liu, H. Y. Ding, and P. Y. Zhang, "Model tests on bearing capacity of composite bucket foundation in clay," Chinese Journal of Geotechnical Engineering, vol. 38, no. 12, pp. 2315-2321, 2016.

[14] N. Jia, P. Zhang, Y. Liu, and H. Ding, "Bearing capacity of composite bucket foundations for offshore wind turbines in silty sand," Ocean Engineering, vol. 151, pp. 1-11, 2018.

[15] H. Ding, Y. Liu, P. Zhang, and C. Le, "Model tests on the bearing capacity of wide-shallow composite bucket foundations for offshore wind turbines in clay," Ocean Engineering, vol. 103, pp. 114-122, 2015.

[16] H. Y. Ding, X. Y. Wang, Y. G. Liu, and P. Y. Zhang, "Study of three-dimensional enveloping surface of wide-shallow composite bucket foundation in sandy soil," Acta Energiae Solaris Sinica, vol. 39, no. 4, pp. 1097-1104, 2018.

[17] X. Wang, P. Zhang, H. Ding, and Y. Liu, "Experimental study on wide-shallow composite bucket foundation for offshore wind turbine under cyclic loading," Marine Georesources and Geotechnology, vol. 37, no. 1, pp. 1-13, 2019.

[18] T. Yu, J. Lian, Z. Shi, and H. Wang, "Experimental investigation of current-induced local scour around composite bucket foundation in silty sand," Ocean Engineering, vol. 117, pp. 311-320, 2016.

[19] X. Chen, T. Liu, and Y. Jiang, "Stability analysis of suction bucket foundations under wave cyclic loading and scouring," Marine Georesources \& Geotechnology, vol. 36, no. 7, pp. 749-758, 2018.

[20] L. G. Lu, R. Liu, J. J. Lian, and G. S. Chen, "Study on vertical ultimate bearing capacity of bucket foundation considering scour effect," Ocean Engineering, vol. 37, no. 3, pp. 69-77, 2019.

[21] M. S. Zhang, X. G. Chen, J. H. Zhang, C. Tian, and Q. Q. Liu, "Bearing capacity analysis of suction bucket foundations after wave loading and scouring," China Energy and Environmental Protection, vol. 40, no. 4, pp. 117-123, 2018.

[22] P. Zhang, S. He, Y. Liu, and H. Ding, "Force transfer characteristics of composite bucket foundation for offshore wind turbines," Journal of Renewable and Sustainable Energy, vol. 8, no. 1, Article ID 013307, 2016.

[23] F. S. C. Tan, Centrifuge and Theoretical Modelling of Conical Footings on Sand, Doctor Degree Dissertation, Cambridge University, Cambridge, UK, 1990.

[24] Q. L. Fan, H. T. Zhao, J. Zheng, and X. Yu, "Stability of bucket foundations under non-coplanar combined loading," Rock and Soil Mechanics, vol. 34, no. 12, pp. 3641-3645, 2013.

[25] X. Feng, M. F. Randolph, S. Gourvenec, and R. Wallerand, "Design approach for rectangular mudmats under fully threedimensional loading," Géotechnique, vol. 64, no. 1, pp. 51-63, 2014.

[26] M. Liu, M. Yang, and H. Wang, "Bearing behavior of wideshallow bucket foundation for offshore wind turbines in drained silty sand," Ocean Engineering, vol. 82, pp. 169-179, 2014.

[27] S. Gourvenec and M. Randolph, "Effect of strength nonhomogeneity on the shape of failure envelopes for combined loading of strip and circular foundations on clay," Géotechnique, vol. 53, no. 6, pp. 575-586, 2003. 
[28] Z. Shen, S. Bie, and L. Guo, "Undrained capacity of a surface circular foundation under fully three-dimensional loading," Computers and Geotechnics, vol. 92, pp. 57-67, 2017.

[29] R. Butterfield, G. T. Houlsby, and G. Gottardi, "Standardized sign conventions and notation for generally loaded foundations," Géotechnique, vol. 47, no. 5, pp. 1051-1054, 1997. 